\title{
DISKUSSIE 2
}

Ds. Thinus Boshoff, Lindley vra aandag vir L. C. Dressel, 1979 DIE $A A N D D I E N S$, Doktorale proefskrif aan UP.

1. Historiese ondersoek na die liturgie-geskiedenis van die aanddiens.

Dressel wy sy doktorale proefskrif aan "Die Aanddiens" met prof. A. C. Barnard as promotor van UP. In sy inleiding wys hy na artikels in Die Kerkblad in 1978, 'n studiestuk van Klassis PretoriaOos in 1974 en dr. Henk Denkema se lesings voor die GTV van Witwatersrand. Hy wys op die universele verskynsel van geleidelike afname in kerkbywoningsyfers, veral wat die aanddiens betref en bespreek die faktore wat daartoe aanleiding gee. Een van die belangrike faktore is die feit dat die aanddiens geen eie karakter naas die oggenddiens het nie. Volgens hom hou $94 \%$ van die Hervormde plattelandse kerke slegs een diens op 'n Sondag. Dressel meen dat die krimpende getal bywoners nie die afskaffing van die aanddiens regverdig nie maar eerder die uitbouing daarvan.

In 'n historiese ontleding van die aanddiens wys Dressel daarop dat die OT Jood die aand as primêr beskou en dat die Pasga by uitstek 'n nagtelike fees was. Die reuk- en brandoffers asook daaglikse gebede vind soggens en saans plaas. Die aansteekseremonies van die tempelkandelare kom later in die geskiedenis weer voor, in die vorm van die Lucernarium. Die Sinagogale erediens vorm die liturgiese oorgang tussen OT en NT en het aldus besondere invloed op latere ontwikkeling. In die Sinagogale erediens in die NT tyd word die ingang en uitgang van die Sabbat (Vrydagen Saterdagaand) gemeenskaplik gevier. Jesus en sy dissipels het die Sabbatdag onderhou. Die aandbyeenkomste kry in NT tyd die hoofklem: Nagmaal is in die aand ingestel; Jesus het telkens in die aand aan die dissipels verskyn; die Sondaagse byeenkomste van die Apostels in Handelinge vind snags plaas; die agapé liefdesmaal van 1 Kor. 11 vind waarskynlik in die aand, voor die nagmaalsviering plaas. Die agapé liefdesmaal het waarskynlik sy wortels in die Joodse Chaburah - 'n gemeenskaplike ete op Vrydagaande voor die aanvang van die Sabbatsviering.

Teen 112 n.C. is die agapé en die nagmaalsviering van mekaar geskei. Die nagmaal is van toe af soggens gevier en tot in die sewende eeu n.C. is die agapé as aandbyeenkoms onderhou waarby streng ordereëls gegeld het soos dat die Biskop teenwoordig moet wees en gewaak moet word teen uitspattighede en rumoer. Hierdie aandbyeenkomste het gepaard gegaan met gebede, 'n gemeenskaplike ete waarby die armes versorg is, gesange en die Lucernarium die aansteekseremonie van die ligte deur die Biskop. Hierdie byeenkomste is dan ook genoem die Lucernarium.

Gesamentlike gebedsbyeenkomste op vasgestelde tye dateer uit die vroegste eeue van die Christelike kerk en teen die vierde 
eeu n.C. het dit al publieke geleenthede geword onder invloed van die Roomse Kerk se Sondagaandse Vespers. Die Vespers kom uiteindelik in die plek van die Lucernarium en terwyl die klooster die gebedsbyeenkomste van die gewone kerkvolk ontneem, ontstaan in Duitsland die sogenaamde Volksandacht - 'n godsdienstige lesing in die volkstaal met skriflesing, gebede en psalmgesang. Die tweede Vatikaanse Konsilie besluit om die gemeente meer te laat deel en openbare gebedsbyeenkomste (Vespers) word 'n instelling. Die Oosterse kerke het die klem laat val op Saterdagaandse Vespers, opgevolg deur nagwake wat kulmineer in die nagmaalviering op die Sondagoggend.

Na die Reformasie van E16 behou die Lutherse, Anglikaanse en Roomse kerke die aandgebedsbyeenkomste terwyl die Gereformeerdes (Calvyn en andere) 'n preekdiens in die plek van die Vespers stel.

By die Lutherse kerke kry die oggenddiens die hoofklem en die aanddiens kry almeer 'n pedagogiese beklemtoning. Luther het die Vespers behou maar uitgebou met die oog op geloofsopbou en die uitleg van die leer deur by die aand se skriflesing (Lectua Continua) 'n skrifuitleg en kategetiese onderrig te voeg. By die Anglikaanse kerk is "morning and evening prayers" onderhou maar mettertyd is daar ook by die aandbyeenkomste gepreek. Die Metodiste wou aanvanklik binne die Anglikaanse kerke kleingroepgemeentes vorm wat soggens voor- en saans na die Anglikaanse byeenkomste bymekaarkom vir gebedsgemeenskap maar na John Wesley se dood (1791) het hulle volwaardige preekdienste in die aand begin hou.

Die klem wat die leerelement kry by middagdienste is kenmerkend van die Gereformeerde Reformatore soos Zwingli, Calvyn Knox en ook die liturgiese ordes van bv. A'Lasco, Paltz en andere. Zwingli is beïnvloed deur die sogenaamde Pronaus - 'n preekdiens in die landstaal en Calvyn, in navolging van Bucer, laat die klem voluit val op die onderrig van die volk. Volgens Dressel het Calvyn geen vaste liturgiese orde vir die middagbyeenkomste gehad nie. Sy dienste is gekenmerk deur gemeentesang (vir ongeveer 'n halfuur), gebede, 'n preek of uitleg en kinderkategese. Die kategismuspreek het dus hier sy oorsprong. Later is die kinderkategese na die week verskuif. Die gebedsbyeenkomste in die aand is vervang deur die familiegebede elke oggend en aand.

Die Nedl. Herv. Kerk het die Reformatore se middagleerdiens en kinderkatkisasie alreeds in die Sinodebesluite van s'Gravenhage 1586 vasgelê en teenoor die Remonstrante te Dordrecht 1618/19 die predikante beveel om elke Sondag uit die kategismus te preek. Die gebedsbyeenkomste het op 'n stadium weer herleef in die vorm van die Getijdedienste maar het finaal doodgeloop in die sewentiende eeu. In die agtiende eeu was die kategismuspreke baie gewild maar teen 1853 moes die sinodes stappe neem om toe te sien dat lidmate dit bywoon. In 1841 is aan visitatore opgedra om kerke te vermaan om weekliks kategismuspreke te hou. Die Geref. Kerke van Nederl. (GKN) verskil nie veel van die Nedl. Herv. nie, behalwe dat hulle in 1965 liturgiese ordes vir die (soms gekombineerde) leer- 
diens en Avondgebed aanvaar het en dat hulle in 'n kerkordeartikel (Art. 70.1) bepaal dat daar 'n tweede diens moet wees.

In Suid-Afrika was daar, soos in Nederland, van 1652 af twee kerkdienste per Sondag. (Jan van Riebeeck het die tweede diens op 'n stadium afgeskaf omdat die mense so hard moes werk in die week!). Daar is genoeg getuienis dat middagdienste waarby die doop bedien is, aan die Kaap gehou is. Hierdie gebruik is ook deur die Voortrekkers op die Groot Trek onderhou.

Die NG Kerk gaan sedert die vasstelling van die Kerkwet in 1862 alreeds uit van die bestaan van die tweede erediens sonder om die aantal dienste per Sondag te bepaal. Die 1902 NG Sinode bepaal dat daar 12 keer per jaar kategismuspreke moet wees en sedert 1953 poog die NG Kerk om sy liturgie te orden. In 1959 is twee liturgiese ordes aangegee vir die tweede diens wat wesenlik dieselfde is as die oggenddienste met weglating van sekere elemente. Van 1966 af poog die NG Kerk om die eie karakter van die aanddiens vas te stel. In 1978 is daar bevind dat daar geen Bybelse imperatief bestaan tot die hou van 'n tweede erediens nie maar dat die aanddiens tog behou en uitgebou word om daaraan 'n eie karakter te gee. Die Ned. Herv. Kerk van Afrika onderhou 'n tweede preekdiens sonder ' $n$ eie karakter. Dit is bevind dat die NHK die tweede diens maklik nalaat.

Die Gereformeerde Kerk(e) sê Dressel, is die enigste van die drie Afrikaanse kerke waar die tweede erediens as egte leerdiens behoue gebly het. Hierdie kerk skenk sedert 1862 aandag aan liturgiese sake en berus sedert 1927 op die liturgie soos vasgestel deur die Sinode van Dordrecht 1618/19. In 1927 is ook bepaal dat die tweede diens 'n kategismuspreek sal bevat. Die Geref. Kerk bedien die doop en nagmaal alternatiewelik soggens of saans.

2. Inrigting van die aanddiens.

In sy derde hoofstuk en verder ondersoek Dressel verskillende gestaltes of eksperimente wat die aanddiens aanneem om dit dan aan die hand van 'n gepostuleerde definisie van erediens te beoordeel. Hy stel dat erediensvorme tyd- en plekgebonde is maar dat die twintigste eeuse Liturgiese Beweging met hul vlaag van eksperimente, veral rondom die aanddiens, eerder liturgievernieling as -vernuwing teweeg gebring het. Meeste eksperimente wil (i) die lidmate meer betrokke maak by die hiturgie deur die outoritêre struktuur te deurbreek en te vervang met dinamiese gemeenskapsbelewing; (ii) vra vir meer aksie in diakonaat deur middel van groepwerk; (iii) die ekumeniese aspekte beklemtoon en (iv) meer moderne sang en musiek hê om aan te pas by die moderne mens. Eksperimente rondom die preek- en leerdiens poog om die (swak) preekkommunikasie te verbeter deur middel van meedoen aan die preekbeplanning, meedoen aan liturgie, vrae en besprekings, konferensies, kleingroepdinamika, en selfs huisgemeentes om die aandkerk te vervang. Groot klem val op skoling en toerusting om die hiturgie te komplimenteer deur die diakonaat in diakonaal-sosiale diens of selfs sosiaal-politiese werkgroepe en aksies. Verskeie eksperimente laat die Vespers, die aandnagmaal en die agapé herleef. Moderne musiek 
konserte en drama, Charismatiese eksperimente, tegniese hulpmiddele en jeugdienste kry almeer plek in die aanddiens.

Ten einde die verskillende gestaltes of eksperimente te beoordeel postuleer Dressel die volgende definisie van erediens: "Liturgie is die ordening van die samekoms van die gemeente (met die oog op die saam-doen) waarin die dinamiek van God's woord plaasvind (H. Jonker) en waarin die gemeente die geleentheid kry om op die dinamiek van God's woord te reageer in skuldbelydenis, aanbidding, lofprysing, geloofsbelydenis, deelname aan-en viering van die heil in die sakramente, gemeenskap, gebed, offergawes en diensbetoon in en buite die samekoms. Alles geskied tot eer en verheerliking van die drie-enige God tot opbou van die gelowige en onder leiding en toesig van die ampte (W.J. de Klerk)". Skrifgebondenheid en belydenisgebondenheid word aangemerk as hoofnorme. Erediens moet altyd ontmoeting tussen God en gemeente wees waarin die mens eers sal luister voor hy antwoord. Daarom is skriflesing en prediking vaste elemente van erediens. Ander wesenstrekke van erediens is die sakramente, geloofsbelydenis, gemeenskap van die geloof, gebede en offergawes. Om erediens te wees, moet dit tot eer van God wees en kan dit nie die opbouing van die geloof en die toesig van die ampte mis nie. Dressel noem maar behandel nie die volgende (kontemporêre) eise aan die erediens gestel naamlik die feestelike karakter, eskatologiese uitstrek na die toekoms, relevansie vir die vandag-mens, holistiese eis om die hele mens in ag te neem.

In sy positiewe en negatiewe beoordeling van die verskillende gestaltes wat die eksperimente aan die aanddiens gee, stel Dressel dit dat die tweede diens (aanddiens) beslis ' $n$ erediens is (moet wees) met ' $n$ eie, unieke karakter. Dit mag nooit blote herhaling van die eerste diens wees met weglating van sekere elemente nie: "Wie die aanddiens bloot ' $n$ herhaling van die eerste diens maak is besig om die grond onder die aanddiens weg te grawe". By elke erediens moet daar skriflesing, gebed, sang en prediking wees waarsonder die erediens se wese aangetas word. Die ander elemente soos sakramente, geloofsbelydenis, wet en skuldbelydenis is opsioneel. Hy waarsku teen verandering net ter wille van die mode van verandering of as lokmiddel om mense in die kerk te kry; teen die oordrewe klem op menslike betrokkendheid en teen ordelose vryheid soos in die "happenings" van die Charismatiese chaos-dienste.

In sy praktiese riglyne vir die vormgewing van die aanddiens wys Dressel weer daarop dat die agteruitgang van die aanddiens te wyte is aan die gebrek aan die formulering van die eie, unieke, besondere karakter daarvan. Die aanddiens moet iets anders wees as die oggenddiens - ook ter wille van die kerkganger wat dan entoesiasties daarna kon opkom. "Wie die aanddiens prysgee, verbeur baie", sê hy. Dressel wys vervolgens op die plurale of meervormige karakter van die aanddiens: Dit is 'n volwaardige erediens met bepaalde verskillende aksente en geen afskeepsgeleentheid nie. Die voorbereiding vir die aanddiens verg beplanning tussen predikant, kerkraad, gemeente en orreliste. Verskillende wisselvorme van die aanderediens word aan die orde gestel waarin telkens 'n ander faset die hoofklem ontvang: Die hoofdiens kan afwisselend in die 
aand gehou word met sakramentsgebruik, wet, skuldbelydenis en geloofsbelydenis. Die preek is onvervangbaar. Ander variasies is om aanddienste te hou met die klem op lering (kategismus- en ander belydenisskrifte-prediking) waarby aansluitend by die preek toeligting gegee kan word oor kontemporêre aktuele onderwerpe deur gebruikmaking van kenners en tegniese hulpmiddele soos films, skyfies ens. Nog 'n variasie is 'n aanderediens met die prominente klem op deelnemende gebed van die kerkgangers. Dressel waarsku teen onordelikheid maar beveel aan dat die gemeente op die voorganger se gebed antwoord (Litanie); dat gebruik gemaak kan word van die Collecta (gebedsversoeke op stukkie papier aan liturg oorhandig); kettinggebede (elkeen sluit daarby aan sonder om Amen te sê); gonsgebede (in groepsbesprekings na die erediens); stilgebed en vrye gebed. Bidure word as legitieme Nuwe Testamentiese gebruik aangewys. ' $n$ Volgende variasie is 'n aanderediens met die klem op sang - 'n sangdiens. Dressel pleit vir variasie in die opgee van liedere en beursang maar waarsku daarteen dat die koor die gemeentesang uitskakel of dat die preek nagelaat word. Sangdienste moet nie ontaard in sangoefeninge nie en kerkkonserte onder die erediens word afgewys. $\mathrm{Na}$ die erediens kan verskillende dinge plaasvind soos simposiums, konferensies, groeps- en paneelbesprekings, volwasse kategese, lesings, kerkkonserte, groepsbyeenkomste, lidmaatskapstoerustingsprogramme, bybelstudie ens. Dressel sê hy volstaan met hierdie variasies omdat dit in ooreenstemming is met die Skrif en die geskiedenis en meen dat as dit in die gemeentes tot verwerkliking kan kom, die aanddiens 'n nuwe tydvak sal beleef.

\section{Onbeantwoorde vrae in Dressel se studie}

3.1 Die historiese ondersoek bewys die oorspronklike hoofklem wat die aanddiens in bybelse tye gehad het en hoe dit eventueel na die oggendsamekomste verskuif het. Dressel laat egter na om indringend in te gaan op die brandende aktuele vraag of die OT aand- en môreoffers normatief is vir die Christelike kerk se oggend- en aanddiens. Die skrywer haal die NG Sinode van 1978 se bevinding aan dat daar geen Bybelse imperatief tot die hou van 'n tweede diens op Sondag bestaan nie maar laat dan ongelukkig na om aan te toon dat die tweede diens nie uit blote pligpleging teenoor 'n ongeskrewe wet of uitgehoorsaamheid aan die tradisie onderhou word nie. Hy veronderstel die tweede erediens sonder om dit wetenskaplik/teologies te bevraagteken of te bewys. Dit verminder die waarde van die studie 'tot 'n blote pragmatiese liturgiegeskiedenis.

3.2 Die historiese ondersoek word opgevolg met 'n fenomenologiese ondersoek na verskillende wisselvorme wat die tweede diens kan inneem na aanleiding van "die eksperimente". Dressel stel dat die tweede diens (aanddiens) beslis 'n EREdiens moet wees sonder om te beredeneer waarom nou juis 'n EREdiens. Sy stelling sou veel meer gewig gedra het as hy byvoorbeeld sy gepostuleerde definisie en norme vir erediens getoets het aan Calvyn se leerdiens (wat egter geen vaste liturgiese orde gehad het nie) om aan te toon of Calvyn en ander Reformatore inderdaad daarvan ' $n$ erediens gemaak 
het al dan nie. Dit is ook jammer dat Dressel die kontemporêre eise rondom 'n erediens soos feestelikheid en eskatologiese uitsig (soos dit byvoorbeeld by Moltmann figureer) nie beoordeel nie. Dit is ook jammer dat 'n skrifuitspraak soos Ps. 27:4, 8 waarin kerkgang as bevel van God, vrug van geloof en middel tot geloofsopbou pragtig geopenbaar word, nêrens eksplisiet aan die orde kom nie.

3.3 Dressel se resultate stel teleur. In wese is dit 'n blote herhaling van die besluite van die NG Sinode van 1978 en van die boek "Die Erediens" van die NG Kerk waaruit lang aanhalings gemaak word. Hy gaan uit van die gebruike in die NG Kerk en stel dit voor (byvoorbeeld die bidure) as legitieme NT. gebruike. Die uiteindelik voorgestelde liturgiese ordes vir die leerdienste, gebedsdienste en sangdienste verskil in wese nog steeds niks van die oggenddienste nie. Dit is nog steeds herhaling van oggenddiens met telkens 'n nuwe aksent of met byvoeging of weglating van sekere elemente. Dressel stel dat die aanddiens erediens is waarby geen eksperimente toegelaat mag word nie maar doen dan self (op grond van gepostuleerde plurale karakter van die aanddiens) verskillende variasies (eksperimente) aan die hand om die tweede diens nie af te skaf nie, maar uit te bou.

3.4 In die Gereformeerde Kerke bestaan die gedagte dat die eerste en tweede erediens wesenlik een is soos blyk uit die weglating van die belydenis en wet in die tweede diens. Die gedagte was dat die Sondag "omraam" moet word deur kerkgang. Die stelling van die eie, unieke, nuwe karakter van die tweede erediens staan dus direk teenoor hierdie eenheidsgedagte. Omdat Dressel se studieresultate gebaseer is op die amptelike standpunt van die NG Kerk, openbaar dit nou 'n verskil in gedagtes tussen die Gereformeerde Kerke en die NG Kerk. Dressel het, soos gesê, egter nie aangetoon waarom die tweede diens inderdaad 'n eie karakter moet hê nie, behalwe om te stel dat die verval van die aanddiens hieraan te wyte is.

3.5 In 'n studie soos hierdie sou mens verwag dat die ondersoeker die hou van 'n tweede erediens direk na die eerste diens (soos wat dit by baie plattelandse gemeentes in gebruik is) prinsipieel en prakties sou ondersoek om hieroor duidelike riglyne te gee. Dressel kom hoegenaamd nie daarby uit nie en ontsnap so aan nog 'n uiters brandend-aktuele vraagstuk. Die verteerbaarheid van twee volbloed preke direk of kort na mekaar, die vermoeienis wat dit vir veral die katkisasiekinders meebring, die feit dat 'n aansienlike deel van die gemeente wat volgens Efs. 4:11, 12 opgebou moet word afwesig is by die tweede diens en die vraag na die tugwaardigheid van wegblyers is alles nog onbeantwoorde vrae.

3.6 Tegnies gesproke moet ten slotte vermeld word dat die proefskrif nie so geredelik beskikbaar is nie. Ek het dit d.m.v. interbiblioteeklening op mikrofiche gelees. 